\title{
Biliopancreatic Endoscopy: New Solutions to Old Issues
}

\author{
Alessandro Fugazza Matteo Colombo Andrea Anderloni \\ Division of Gastroenterology and Digestive Endoscopy, Humanitas Research Hospital - IRCCS, Milano, Italy
}

Keywords

Interventional EUS · EUS biliary drainage · Failed ERCP

\section{Endoscopia biliopancreática: novas soluções para velhos problemas}

\section{Palavras-chave}

Ecoendoscopia de intervenção · Drenagem biliar por ecoendoscopia . Colangiopancreatografia retrógrada endoscópica falhada

Recently, endoscopic retrograde cholangiopancreatography (ERCP) and endoscopic ultrasound (EUS) connections are becoming much more intense, and now the two procedures are considered complementary, supporting the concept of biliopancreatic endoscopy. The introduction of new technologies, instruments, and dedicated devices led us to face new indications and pose new questions.

In this issue of GE - Portuguese Journal of Gastroenterology, 3 case reports are published reporting interesting solutions on different aspects of biliopancreatic diseases.

Firstly, Flor de Lima et al. [1] described a rescue EUSgallbladder drainage (EUS-GBD) as an alternative approach for biliary decompression due to cholangiocarcinoma after failed ERCP.

As reported in the aforementioned case report, EUSGBD is currently one of the possibilities to obtain biliary drainage in malignant biliary obstruction, which is not

Karger@karger.com www.karger.com/pjg

Karger"
C 2022 The Author(s).

Published by S. Karger AG, Basel

This is an Open Access article licensed under the Creative Commons Attribution-NonCommercial-4.0 International License (CC BY-NC) (http://www.karger.com/Services/OpenAccessLicense), applicable to the online version of the article only. Usage and distribution for commercial purposes requires written permission. suitable for other endoscopic treatments after failed ERCP [2]. Particularly, this approach can be very helpful when alternative interventions through the common bile duct (CBD), as EUS choledochoduodenostomy, are not feasible due to insufficient dilation of the CBD $(<10 \mathrm{~mm})$ or the distance between the duodenal wall and the CBD is greater than $10 \mathrm{~mm}$ [3].

EUS interventional procedures were implemented in clinical practice following the development and introduction of single-step lumen apposing metal stent (LAMS) delivery systems, making the procedure simpler and safer without using any ancillary devices [4]. In this regard, Imai et al. [5] published data of 12 patients with obstructive jaundice. The patients were regarded as non-surgical candidates due to the malignant distal biliary stricture and were treated with EUS-GBD after ERCP failure. The rates of technical success, clinical success, and adverse events (AEs) were 100, 91.7, and 16.7\%, respectively; patients survived for a median time of 105 days after the index procedure [5]. Furthermore, Issa et al. [6] published a multicenter retrospective study performed on 28 patients with unresectable malignant distal bile duct obstruction who underwent EUS-GBD drainage. The technical success rate was $100 \%$, whereas only 5 patients experienced AEs ( 3 food impaction and 2 delayed bleeding), all of which were graded as moderate and successfully managed endoscopically. Clinical success, defined as a decrease in serum bilirubin of $>50 \%$ within 2 weeks compared to the basal value, was achieved in 26 patients (93\%). During follow-up, none of the other patients de- 
veloped AEs or jaundice recurrence [6]. EUS-GBD is considered a therapeutic alternative option not only in case of malignant conditions but also in patients with acute cholecystitis deemed unfit for surgery [7]. In this particular setting, EUS-GBD performs as good as percutaneous drainage, providing fewer AEs, shorter hospital stay, and fewer re-interventions [8]. Likewise, Leal et al. [9] showed a biliary drainage after EUS-guided rendezvous procedure after ERCP failure due to the presence of an indwelling biliary uncovered self-expandable metallic stent.

ERCP is still regarded as the procedure of choice for the management of biliary diseases. However, to assess the biliary tract, a trans-papillary approach is not always feasible and can be technically challenging. EUS-guided approaches should then be taken into account, and EUS-guided rendezvous represents one option. In the present case report, one of the possible routes to access the biliary tree is described: puncturing the left intrahepatic bile duct from the stomach. Furthermore, Matsubara et al. [10] proposed an algorithm for the selection of the most appropriate route when facing EUS-guided rendezvous technique. However, in the current literature, there are no conclusive data on this specific topic, but Shiomi Hideyuki et al. [11] published a multicenter prospective study on patients with biliary disorders treated with EUS-guided rendezvous technique as a salvage method after an unsuccessful biliary cannulation achieving a technical success rate of $85 \%$ with an overall AEs rate of $15 \%$. The authors state that EUS-guided rendezvous technique might be considered a safe and feasible salvage option after failed ERCP [11]. Moreover, in these patients with failed ERCP and malignant biliary stricture without the possibility to access the CBD, another EUS procedure to achieve a complete biliary drainage away from the neoplastic stenosis can be considered the EUS hepaticogastrostomy (EUS-HGS). The EUS-HGS allows drainage of the left biliary tree through the hepatic segment II-III across the gastric wall.

Data on efficacy and safety of EUS-HGS from several studies are encouraging $[12,13]$. However, as highlighted by experts, the procedure is still challenging at every technical step and could be burdened by serious intra-procedural AEs [14].

The last case report by Kitagawa [15] showed an endoscopic restoration of a dehiscent pancreatojejunostomy by a transluminal entero-ERCP approach with plastic stent placement. A leakage at the site of a pancreatic anastomosis is one of the most common and feared major AEs that may occur after pancreatic surgery. Current management of this type of complication includes multiple options, ranging from conservative treatment to interventional approach with percutaneous or endoscopic drainage and even a surgical second look [16]. There are no standardized treatment algorithms, and the evidence regarding the role of endoscopy in this particular type of patients is scarce. The main options that endoscopy can offer for the management of patients with surgically altered anatomy are transluminal by entero-ERCP and transmural approach under EUS guidance $[17,18]$. In the case report presented, whilst acknowledging the planning executed and careful rational choice of equipment used (e.g., adding a transparent cap to the tip of the endoscope), the authors managed to obtain direct access of the pancreaticojejunal anastomosis and the successful placement of a pancreatic stent, thus achieving complete resolution of the pancreatic fistula.

Endoscopic therapeutic procedures carried out under EUS guidance represent one of the cornerstones in the management of different disorders of the bilio-pancreatic tract, whether they are benign or malignant. With the development of high-performance echo-endoscopes and the marketing of dedicated devices such as LAMS, the range of options available for interventional endoscopists has certainly expanded. While praising the wide range of access points to the biliary tree available from the gastrointestinal tract, EUS-guided procedures might be tailored to match individual patient needs owing to the continuous improvement of present technologies and the initiative of a few pioneers to explore uncharted lands (e.g., EUS-guided gastro-enterostomy, EUS-guided tumor ablation, and EUS-guided vascular intervention). Gastrointestinal scientific societies are also taking steps to be able to implement interventional EUS techniques into clinical practice, as demonstrated by the "White Paper" newly generated by the American Gastroenterological Association [19]. As recently emphasized [20], one of the essential directives will be the training of tomorrow's operators. Certified training programs under the supervision of experienced tutors will guarantee the development of a comprehensive curriculum with hands-on sessions as an utmost requirement to advance the practice.

\section{Conflict of Interest Statement}

Alessandro Fugazza and Andrea Anderloni are consultants for Boston Scientific and Olympus. Matteo Colombo has no conflict of interest to declare.

Funding Sources

None.
GE Port J Gastroenterol 2022;29:77-79 DOI: $10.1159 / 000521630$
Fugazza/Colombo/Anderloni 


\section{References}

1 Flor de Lima M, Nunes N, Chálim Rebelo C, Moura DB, Pereira JR, Duarte MA. Palliative EUS-guided gallbladder drainage as a salvage treatment of biliary obstruction in inoperable cholangiocarcinoma. GE Port J Gastroenterol. 2021.

2 Fugazza A, Troncone E, Amato A, Tarantino I, Iannone A, Donato G, et al. Difficult biliary cannulation in patients with distal malignant biliary obstruction: an underestimated problem? Dig liver Dis. 2021 Aug.

3 Anderloni A, Fugazza A, Troncone E, Auriemma F, Carrara S, Semeraro R, et al. Singlestage EUS-guided choledochoduodenostomy using a lumen-apposing metal stent for malignant distal biliary obstruction. Gastrointest Endosc. 2019 Jan;89(1):69-76.

4 Rana SS. Endoscopic ultrasound-guided gallbladder drainage: a technical review. Ann Gastroenterol. 2021;34(2):142-8.

5 Imai H, Kitano M, Omoto S, Kadosaka K, Kamata K, Miyata T, et al. EUS-guided gallbladder drainage for rescue treatment of malignant distal biliary obstruction after unsuccessful ERCP. Gastrointest Endosc. 2016 Jul; 84(1):147-51.

6 Issa D, Irani S, Law R, Shah S, Bhalla S, Mahadev S, et al. Endoscopic ultrasound-guided gallbladder drainage as a rescue therapy for unresectable malignant biliary obstruction: a multicenter experience. Endoscopy. 2021 Aug;53(8):827-31.

7 Fugazza A, Colombo M, Repici A, Anderloni A. Endoscopic ultrasound-guided gallbladder drainage: current perspectives. Clin Exp Gastroenterol. 2020;13:193-201.
8 Luk SW, Irani S, Krishnamoorthi R, Wong Lau JY, Wai Ng EK, Teoh AY. Endoscopic ultrasound-guided gallbladder drainage versus percutaneous cholecystostomy for high risk surgical patients with acute cholecystitis: a systematic review and meta-analysis. Endoscopy. 2019 Aug;51(8):722-32.

9 Leal T, Antunes P, da Silva Mendes S, Gonçalves R, Gonçalves B. Palliative biliary drainage using endoscopic ultrasound-guided rendezvous procedure by transgastric approach. GE Port J Gastroenterol. 2021:1.

10 Matsubara S, Nakagawa K, Suda K, Otsuka T, Isayama $\mathrm{H}$, Nakai $\mathrm{Y}$, et al. A proposed algorithm for endoscopic ultrasound-guided rendezvous technique in failed biliary cannulation. J Clin Med. 2020 Nov;9(12):3879.

11 Shiomi H, Yamao K, Hoki N, Hisa T, Ogura T, Minaga K, et al. Endoscopic ultrasoundguided rendezvous technique for failed biliary cannulation in benign and resectable malignant biliary disorders. Dig Dis Sci. 2018 Mar; 63(3):787-96.

12 Winkler J, Caillol F, Ratone JP, Bories E, Pesenti C, Giovannini M. Feasibility of EUSguided hepaticogastrostomy for inoperable malignant hilar biliary strictures. Endosc Ultrasound. 2021 Jan-Feb;10(1):51-6.

13 Nakai Y, Sato T, Hakuta R, Ishigaki K, Saito $\mathrm{K}$, Saito $\mathrm{T}$, et al. Long-term outcomes of a long, partially covered metal stent for EUSguided hepaticogastrostomy in patients with malignant biliary obstruction (with video). Gastrointest Endosc. 2020 Sep;92(3):6231.e1.
14 Bang JY, Varadarajulu S. The promise of EUS-guided hepaticogastrostomy: miles to go before we sleep and miles to go before we sleep. Gastrointest Endosc. 2020 Sep;92(3): 632-3.

15 Kitagawa S. Endoscopic restoration of a dehiscent pancreatojejunostomy after pancreatoduodenectomy. GE Port J Gastroenterol. 2021:1

16 Bassi C, Marchegiani G, Dervenis C, Sarr M, Abu Hilal M, Adham M, et al. The 2016 update of the International Study Group (ISGPS) definition and grading of postoperative pancreatic fistula: 11 years after. Surgery. 2017 Mar;161(3):584-91.

17 Jürgensen C, Distler M, Arlt A, Brückner S, Ellrichmann M, Matthes K, et al. EUS-guided drainage in the management of postoperative pancreatic leaks and fistulas (with video). Gastrointest Endosc. 2019 Feb;89(2):3119.e1.

18 Fugazza A, Anderloni A, Paduano D, Badalamenti M, Maselli R, Carrara S, et al. Underwater cap-assisted endoscopic retrograde cholangiopancreatography in patients with surgically altered anatomy: a pilot study. Endoscopy. 2021 Sep;53(9):927-31.

19 DeWitt JM, Arain M, Chang KJ, Sharaiha R, Komanduri S, Muthusamy VR, et al. Interventional endoscopic ultrasound: current status and future directions. Clin Gastroenterol Hepatol. 2021 Jan;19(1):24-40.

20 Bang JY, Hawes R, Varadarajulu S. Endoscopic biliary drainage for malignant distal biliary obstruction: Which is better - endoscopic retrograde cholangiopancreatography or endoscopic ultrasound? Dig Endosc. 2021 Nov 8. Epub ahead of print. 